\title{
ADUBAÇÃO COM SILÍCIO COMO FATOR DE RESISTÊNCIA A INSETOS-PRAGA E PROMOTOR DE PRODUTIVIDADE EM CULTURA DE BATATA INGLESA EM SISTEMA ORGÂNICO
}

\author{
Fertilization with silicon as resistance factor to pest insects and promoter of productivity \\ in the potato crop in an organic system
}

\author{
Flávia Batista Gomes ${ }^{1}$, Jair Campos Moraes², Danila Kelly Pereira Neri ${ }^{3}$
}

\begin{abstract}
RESUMO
O cultivo orgânico de batata inglesa apresenta viabilidade econômica, porém enfrenta problemas em relação à manutenção da sanidade. Este trabalho foi realizado para verificar o efeito da adubação com silício na incidência de insetos-praga e na produtividade da cultura da batata inglesa em sistema orgânico. Foram testados 5 tratamentos com 4 repetições: 1- testemunha; 2- adubação via solo com ácido silícico, na dose correspondente a 0,35 t.ha $^{-1} ; 3$ - adubação via foliar com solução de ácido silícico a $0,35 \%$; 4- adubação via solo com pó de rocha, na dose correspondente a 2 t.ha ${ }^{-1} ; 5$-adubação via foliar com solução de pó de rocha a $2 \%$. Os tratamentos foram aplicados 20 dias após o plantio da batata-semente. Foi monitorada a incidência de insetos-praga por meio da determinação do número pulgões, de lesões foliares provocadas por Diabrotica speciosa (Germar) e de folíolos minados por Liriomyza spp.. Determinaram, ainda, a altura e o diâmetro das plantas e a produtividade. Verificou-se que as plantas adubadas com silício, independentemente da forma de aplicação e da fonte utilizada, apresentaram menor número de injúrias foliares em relação àquelas da testemunha. Contudo, não foi constatado o efeito da adubação com silício no desenvolvimento e produtividade da cultura.
\end{abstract}

Termos para indexação: Silício, batata orgânica, resistência de plantas a insetos, controle de pragas.

\begin{abstract}
The organic cultivation of potato presents economical viability, however it faces problems in relation to the maintenance of sanity. This work was carried out to verify the effect of the silicon fertilization on the incidence of pest insects and in the productivity of potato in an organic system. Five treatments were tested, with four replications: 1- control; 2- fertilization applied via soil with silicic acid, in the dose corresponding to 0.35 t.ha $^{-1} 3$ - fertilization applied via leaf with solution of silicic acid at $0.35 \%$; 4- fertilization applied via soil with rock powder, in the dose corresponding to 2 t.ha ${ }^{-1} ; 5$ - fertilization applied via leaf with rock powder solution at $2 \%$. The treatments were applied 20 days after the plantation of the seed potato. The incidence of pest insects was monitored by means of the determination of the number of foliar lesions caused by Diabrotica speciosa (Germar) and the number of leaves mined by Liriomyza spp. The diameter and the height of the plants and the productivity were determined. Independently of the form of application and the source used, it was verified that the plants fertilized with silicon presented lower number of leaf injuries in relation to the control ones. However, it was not possible to verify the effect of the fertilization with silicon on the development and productivity of the culture.
\end{abstract}

Index terms: Silicon, organic potato, insect plant resistance, pest control.

(Recebido em 26 de março de 2007 e aprovado em 27 de março de 2008)

\section{INTRODUÇÃO}

O processo de modernização da agricultura, ocorrido principalmente a partir dos anos 50, desvalorizou os processos naturais e biológicos e priorizou a automecânica, os adubos sintéticos e os agrotóxicos (SOUZA \& RESENDE, 2003), gerando problemas ambientais que afetam negativamente o controle de insetospraga.

Neste contexto, a prática de uma agricultura que preserve os recursos naturais e otimize a produtividade tem se tornado cada vez mais necessária, destacando-se o sistema orgânico de produção. A agricultura orgânica tem apresentado um crescimento mundial expressivo, principalmente em área plantada e oferta de produtos (SOUZA \& RESENDE, 2003). O mercado de produtos orgânicos tem crescido a uma taxa média de $30 \%$ ao ano, existindo, porém, exemplos de crescimentos mais expressivos que superam $100 \%$ ao ano. Atualmente, o Brasil ocupa a segunda posição mundial em termos de área manejada organicamente (6,5 milhões de hectares), sendo

\footnotetext{
'Engenheira Agronômica, Doutora em Entomologia - Rua Benigno de Souza, 56 - Morro do Pau D'Óleo - 35920-000 - Nova Era, MG - fg.batista@bol.com.br 'Engenheiro Agronômico, Doutor em Fitotecnia - Departamento de Entomologia/DEN - Universidade Federal de Lavras/UFLA - Cx. P. 3037 - 37200-000 Lavras, MG - jcmoraes@ufla.br

${ }^{3}$ Engenheira Agronômica, Doutora em Entomologia - Departamento de Agroecologia e Informática - Unidade de Ensino Descentralizada de Ipanguaçu/ CEFET-RN - Povoado Base Física, s/n - Zona Rural - 59508-000 - Ipanguaçu, RN - danilaneri@yahoo.com.br
} 
900 mil hectares destinados à agropecuária orgânica e o restante ao extrativismo sustentável. Da produção orgânica brasileira, 75\% são exportados gerando, em 2006, cerca de US\$ 1 bilhão (INSTITUTO BIODINÂMICO, 2007).

Nos últimos 30 anos a produção do Brasil de batata inglesa cresceu $70 \%$, sendo está importante na dieta alimentar brasileira, principalmente nas regiões $\mathrm{Sul}$ e Sudeste, bem como para o mundo. No cultivo da batateira normalmente utilizam-se grandes quantidades de fertilizantes químicos e produtos fitossanitários (IAPAR, 2000). Os agroquímicos representam a maior parte dos gastos com insumos dessa cultura, representando $46 \%$ do custo de produção (AGRIANUAL, 2007). O sistema orgânico de produção de batata inglesa apresenta uma menor produtividade em relação ao convencional, mas uma viabilidade econômica e relação benefício/custo superior ao sistema convencional. Entretanto, o cultivo orgânico de batata inglesa depende da sanidade da cultura em relação à pragas e doenças para obtenção de melhores produtividades (DAROLT et al., 2003).

Dentre as pragas potenciais da cultura da batata destacam-se o pulgão Myzus persicae (Sulzer, 1776), que além de succionar a seiva das plantas, podendo diminuir o crescimento vegetativo e o tamanho dos tubérculos, é vetor de fitovírus (PETITT \& SMILOWITZ, 1982; SOUZA-DIAS, 1995); o coleóptero Diabrotica speciosa (Germar, 1824), chamado vulgarmente de "vaquinha", cujos adultos se alimentam das folhas, causando danos nas fases de brotação e emergência das hastes, o que pode acarretar perdas significativas na produção (CRANSHAW \& RADCLIFFE, 1980); as larvas, conhecidas como "larvasalfinete" que atacam as raízes e perfuram os tubérculos, depreciando-os para a comercialização (GASSEN, 1989); e a mosca minadora Liriomyza spp., cujas larvas minam as folhas das plantas, diminuindo a área fotossintética e reduzindo o peso e o tamanho dos tubérculos (SOUZA et al., 1998).

Os efeitos benéficos do silício têm sido demonstrados em várias espécies de plantas, e no caso de problemas fitossanitários, é capaz de aumentar a resistência das plantas ao ataque de insetos e patógenos (EPSTEIN, 2001). O silício pode conferir resistência às plantas pela sua deposição, formando uma barreira mecânica (GOUSSAIN, 2002; YOSHIDA et al., 1962), e/ou pela sua ação como elicitor do processo de resistência induzida (FAWE et al., 2001; GOMES et al., 2005). Além disso, os benefícios proporcionados pela adubação silicatada podem resultar em ganhos de produtividade (NOJOSA et al., 2006). Contudo, a indução de resistência nas plantas aloca recursos para a síntese de compostos de defesa, tornando- se necessário, a verificação de possíveis quedas de produtividade (DÉLANO-FRIER et al., 2004).

Dessa forma, neste trabalho objetivou-se verificar o efeito da adubação com silício na incidência de insetospraga e suas injúrias e algumas características agronômicas de batata inglesa em sistema orgânico.

\section{MATERIALE MÉTODOS}

O experimento foi conduzido a campo, na época das águas, no setor de Horticultura da Universidade Federal de Lavras, no período de outubro de 2006 a janeiro de 2007. O solo, em área destinada ao cultivo orgânico, foi preparado por meio de aração e gradagem.

A batata-semente, cultivar Éden, foi plantada em sulcos espaçados de $0,8 \mathrm{~m}$ e $0,25 \mathrm{~m}$ entre plantas. Cada parcela era constituída por quatro linhas de $3 \mathrm{~m}$, sendo a área útil as duas linhas centrais, deixando-se $0,4 \mathrm{~m}$ de cada lado como bordadura.

A adubação foi realizada com composto orgânico, 30 t/ha, incorporado no sulco de plantio. Foram realizadas capinas manuais, sendo a primeira realizada juntamente com a amontoa, 30 dias após o plantio.

Tratamentos. Foram testados os seguintes tratamentos: 1- testemunha; 2- adubação via solo com ácido silícico, na dosagem correspondente a $0,35 \mathrm{t} / \mathrm{ha}(0,35 \mathrm{t} / \mathrm{ha}$ de $\left.\mathrm{SiO}_{2}\right)$; 3- adubação via foliar com solução de ácido silícico a $0,35 \%$; 4- adubação via solo com pó de rocha (Biocksil $^{\circledR}$, contendo $17,43 \%$ de $\mathrm{SiO}_{2}, 9,82 \%$ de $\mathrm{S}, 1,31 \%$ de $\mathrm{CaO}, 0,18 \%$ de $\mathrm{MgO}, 0,16 \%$ de $\mathrm{Fe}_{2} \mathrm{O}_{3}$ e $0,10 \%$ de $\mathrm{P}_{2} \mathrm{O}_{5}$ ), na dosagem correspondente a $2 \mathrm{t} / \mathrm{ha}\left(0,35 \mathrm{t}^{-\mathrm{ha}^{-1}} \mathrm{de}^{\mathrm{SiO}}\right)$; e 5 adubação via foliar com solução de pó de rocha a $2 \%$.

Os tratamentos via solo foram aplicados 20 dias após o plantio, diluídos em água, e após uma semana, incorporados junto às linhas das plantas. $\mathrm{Na}$ aplicação via foliar, o silício foi diluído em água, nas respectivas concentrações, e pulverizado nas plantas até o escorrimento da calda. A aplicação foliar foi realizada semanalmente, iniciando-se uma semana após a emergência das hastes até a fase final de tuberização, num total de oito aplicações.

Monitoramento dos insetos-praga. Aos 30, 60 e 80 dias após a emergência das plantas foi monitorada a presença do pulgão M. persicae por meio de amostragens, contando-se os pulgões presentes em cinco plantas, ao acaso, por parcela.

Para verificar as injúrias foliares causadas por $D$. speciosa, aos 30 dias após a emergência das hastes, quando, visualmente, foi observado um pico populacional deste inseto-praga no batatal, foi realizada uma amostragem contando-se as lesões presentes na terceira folha de cinco 
plantas por parcela. Aos 60 dias após a emergência das brotações, quando se intensifica a fase de tuberização, foi realizada a contagem de folíolos minados pela moscaminadora Liriomyza spp.

Determinação da altura e do diâmetro das plantas. Aos 60 dias após a emergência das brotações, fase de tuberização, foram determinados a altura das plantas, com auxílio de uma trena, e o diâmetro das hastes, utilizando-se um paquímetro, em cinco plantas escolhidas aleatoriamente por parcela.

Avaliação da produtividade. A cultura foi conduzida até o final do ciclo e, após a colheita, os tubérculos foram lavados e pesados, sendo a produtividade calculada em tonelada por hectare.

Estatística. Adotou-se o delineamento em blocos casualizados, com 5 tratamentos e 4 repetições. Os dados foram submetidos à análise de variância, sendo que os de contagem de insetos foram transformados em $\sqrt{X+0,5}$. As médias foram comparadas pelo teste de Scott \& Knott (1974) a 5\% de significância.

\section{RESULTADOS E DISCUSSÃO}

Monitoramento de insetos-praga. Não foi visualizada a ocorrência de M. persicae, possivelmente pela alta precipitação ocorrida na região durante o cultivo (Tabela 1). Problemas com ataque de pulgões em batata inglesa estão relacionados a fatores climáticos, que influenciam sua dinâmica populacional (Bertels et al., 1971). A chuva ocorrida durante o cultivo da batateira pode ter desempenhado efeito supressivo sobre a população de pulgões, afetando sua movimentação e vôo (Carvalho et al., 2002; Pinto et al., 2000).

Em relação ao número de lesões foliares ocasionadas por $D$. speciosa foi observado, na testemunha, um número cerca de duas vezes maior que nas plantas adubadas com silício, as quais não diferiram significativamente entre si (Tabela 2).

As plantas que não receberam silício (testemunha) também apresentaram maior número de folíolos minados por Liriomyza spp. em relação aos demais tratamentos (Tabela 2). Goussain et al. (2002) verificaram que a aplicação foliar de silicato de sódio em plantas de milho causou aumento da mortalidade e do canibalismo de lagartas Spodoptera frugiperda (J. E. Smith, 1797) em razão do aumento da deposição de silício na parede celular das folhas, formando, possivelmente, uma barreira mecânica capaz de aumentar a dureza dos tecidos foliares e desgastar acentuadamente as mandíbulas das lagartas e, portanto, dificultar sua alimentação. Também a aplicação de silicato

Tabela 1 - Dados meteorológicos: temperatura (média mensal), umidade relativa (média mensal) e precipitação (mensal acumulada) de outubro/2006 a janeiro/2007, ocorridos durante a condução do experimento*. Lavras - MG. 2007.

\begin{tabular}{lccccc}
\hline \multirow{2}{*}{ Meses } & \multicolumn{3}{c}{ Temperatura $\left({ }^{\circ} \mathrm{C}\right)$} & Umidade & $\begin{array}{c}\text { Precipitação } \\
(\mathrm{mm})\end{array}$ \\
\cline { 2 - 4 } & Média & Máxima & Mínima & \\
\hline Outubro & 21,2 & 27,3 & 16,9 & 77,9 & 108,5 \\
Novembro & 21,3 & 28,0 & 17,4 & 77,1 & 261,0 \\
Dezembro & 22,8 & 28,5 & 18,7 & 79,1 & 220,1 \\
Janeiro & 21,9 & 27,6 & 18,7 & 85,7 & 554,9 \\
\hline
\end{tabular}

*Fonte: Estação meteorológica da UFLA - 2007.

Tabela 2 - Número de lesões foliares (média \pm erro padrão) causadas por Diabrotica speciosa e número de folíolos minados (média \pm erro padrão) por Liriomyza spp. em plantas de batata inglesa adubadas com silício. Lavras - MG. 2006.

\begin{tabular}{lcc}
\hline \multicolumn{1}{c}{ Tratamentos } & $\begin{array}{c}\mathrm{N}^{\mathrm{o}} \text { de lesões por planta } \\
\text { ocasionadas por } \text { D. speciosa }\end{array}$ & $\begin{array}{c}\text { № de folíolos minados por planta } \\
\text { por Liriomyza } \text { spp }\end{array}$ \\
\hline Testemunha & $5,00 \pm 0,17 \mathrm{a}$ & $1,75 \pm 0,13 \mathrm{a}$ \\
Ácido silícico via solo & $2,60 \pm 0,17 \mathrm{~b}$ & $0,50 \pm 0,14 \mathrm{~b}$ \\
Ácido silícico via foliar & $2,50 \pm 0,26 \mathrm{~b}$ & $1,00 \pm 0,20 \mathrm{~b}$ \\
Pó de rocha via solo & $2,85 \pm 0,24 \mathrm{~b}$ & $0,25 \pm 0,13 \mathrm{~b}$ \\
Pó de rocha via foliar & $2,45 \pm 0,21 \mathrm{~b}$ & $0,50 \pm 0,14 \mathrm{~b}$ \\
\hline
\end{tabular}

Médias seguidas de mesma letra minúscula na coluna não diferem estatisticamente entre si pelo teste de Scott-Knott $(\mathrm{P} \leq 0,05)$. 
de potássio em crisântemo aumentou a resistência das plantas ao ataque da mosca minadora Liriomyza trifolii (Burgess, 1880), diminuindo significativamente a emergência de adultos nas plantas tratadas com silício (PARRELA \& COSTAMAGNA, 2006).

O silício, além de atuar como barreira mecânica, pode agir como elicitor do processo de indução de resistência, aumentando a atividade de enzimas relacionadas à defesa das plantas de trigo, a peroxidase, a polifenoloxidase e a fenilalanina amônia-liase (GOMES et al., 2005).

A utilização do silício, independentemente da forma de aplicação e da fonte utilizada, aumentou a resistência das plantas de batata inglesa a $D$. speciosa e a Liriomyza spp., possivelmente em razão do seu acúmulo e polimerização na parede celular, aumentando a rigidez dos tecidos foliares e dificultando a alimentação, e/ou a indução de moléculas defensivas como taninos e lignina, entre outras substâncias de defesa.

Altura e diâmetro das plantas. Não foram observadas diferenças significativas entre os tratamentos para altura e diâmetro das hastes das plantas (Tabela 3). Contudo, em milho, a aplicação de silício não afetou a altura das plantas, mas aumentou o diâmetro do caule (NERI, 2006).

O silício é um elemento mineral que, depois de absorvido pelas plantas, polimeriza-se e acumula na parede celular da epiderme (JARVIS, 1987) e dos tecidos de suporte e sustentação, fortalecendo significativamente a estrutura da planta decorrente do fortalecimento do caule (PLUCKNETT, 1971). Dentre os benefícios proporcionados pela adubação com silício destaca-se sua influência positiva no crescimento e desenvolvimento das plantas. Porém, este efeito não foi observado no crescimento e desenvolvimento das plantas de batata inglesa, talvez porque elas não sejam consideradas acumuladoras de silício (MA et al., 2001).

Produtividade da cultura. Não foram observadas diferenças significativas entre os tratamentos em relação à produção de tubérculos (Tabela 4).

Contudo, resultados de aumentos de produtividade pela aplicação de silício foram observados em cana-deaçucar (KORNDÖRFER et al., 2002) e em arroz (CARVALHO-PUPATTO et al., 2004).

$\mathrm{Na}$ ausência de estresses ambientais ou nutricionais, a aplicação de silício no solo pode não trazer benefícios às plantas, como o verificado na produção de arroz em solução nutritiva (SILVA \& BOHNEN, 2003). Neste experimento, os benefícios proporcionados pela adubação silicatada em relação ao crescimento e à produtividade podem não ter sido observados em razão da baixa incidência de insetos-praga na cultura decorrente do excesso de chuvas. Além disso, os efeitos benéficos da adubação silicatada em relação ao crescimento,

Tabela 3 - Altura e diâmetro (média \pm erro padrão) das plantas de batata inglesa adubadas com silício. Lavras - MG. 2006.

\begin{tabular}{lcc}
\hline \multicolumn{1}{c}{ Tratamentos } & Altura $(\mathrm{cm})$ & Diâmetro $(\mathrm{cm})$ \\
\hline Testemunha & $54,40 \pm 1,77 \mathrm{a}$ & $0,75 \pm 0,02 \mathrm{a}$ \\
Ácido silícico via solo & $63,55 \pm 1,15 \mathrm{a}$ & $0,94 \pm 0,02 \mathrm{a}$ \\
Ácido silícico via foliar & $60,80 \pm 1,47 \mathrm{a}$ & $0,83 \pm 0,04 \mathrm{a}$ \\
Pó de rocha via solo & $60,30 \pm 1,45 \mathrm{a}$ & $0,96 \pm 0,03 \mathrm{a}$ \\
Pó de rocha via foliar & $62,45 \pm 1,28 \mathrm{a}$ & $0,91 \pm 0,03 \mathrm{a}$ \\
\hline
\end{tabular}

Médias com diferenças não significativas pelo teste $\mathrm{F}(\mathrm{P} \leq 0,05)$.

Tabela 4 - Produtividade (média \pm erro padrão) do cultivo de batata inglesa adubada com silício em sistema orgânico. Lavras - MG. 2007.

\begin{tabular}{lc}
\hline \multicolumn{1}{c}{ Tratamentos } & Produtividade (t.ha $^{-1}$ ) \\
\hline Testemunha & $23,40 \pm 2,14 \mathrm{a}$ \\
Ácido silícico via solo & $23,67 \pm 1,58 \mathrm{a}$ \\
Ácido silícico via foliar & $25,21 \pm 2,80 \mathrm{a}$ \\
Pó de rocha via solo & $26,33 \pm 2,57 \mathrm{a}$ \\
Pó de rocha via foliar & $25,03 \pm 2,50 \mathrm{a}$ \\
\hline
\end{tabular}

Médias com diferenças não significativas pelo teste $\mathrm{F}(\mathrm{P} \leq 0,05)$. 
desenvolvimento e produtividade estão, quase sempre, correlacionados com espécies vegetais classificadas como acumuladoras de silício, incluindo nesta categoria o arroz, a cana-de-açúcar e as gramíneas forrageiras, sendo a batata inglesa classificada como não-acumuladora (MA et al., 2001).

Por outro lado, considerando o silício como sendo um elicitor do processo de resistência induzida, pode-se constatar que o custo metabólico para síntese de compostos de defesa não alterou a produtividade da cultura de batata inglesa, a qual foi acima da média nacional (22 t/ha) (AGRIANUAL, 2007).

\section{CONCLUSÃO}

A aplicação de silício, mesmo em condições adversas de temperatura e precipitação, contribuiu para a redução das injúrias de dois importantes desfolhadores, D. speciosa e Liriomyza spp., e não influenciou a produtividade da cultura da batateira em sistema orgânico. Entretanto, torna-se necessária a condução de outras pesquisas para se obterem subsídios que possam viabilizar a recomendação desta tática de manejo em cultivos de batata inglesa no sistema orgânico.

\section{AGRADECIMENTOS}

Ao Conselho Nacional de Desenvolvimento Científico e Tecnológico - CNPq e à Coordenação de Aperfeiçoamento de Pessoal de Nível Superior - CAPES pela concessão de bolsas e à Fundação de Amparo à Pesquisa de Minas Gerais - FAPEMIG pelo apoio financeiro ao projeto.

\section{REFERÊNCIAS BIBLIOGRÁFICAS}

AGRIANUAL. Anuário da agricultura brasileira. São Paulo: FNP Consultoria e Comércio, 2007. 516 p.

BERTELS, A.; FERREIRA, E.; CASAGRANDE, W. Problemas de vetores de vírus da batata e seu combate nas condições do Rio Grande do Sul. Pesquisa Agropecuária Brasileira, Rio de Janeiro, v. 6, p. 291-306, 1971.

CARVALHO, L. M.; BUENO, V. H. P.; MARTINEZ, R. P. Levantamento de afídeos alados em plantas hortícolas em Lavras - MG. Ciência e Agrotecnologia, Lavras, v. 26, n. 3, p. 523-532, maio/jun. 2002.

CARVALHO-PUPATTO, J. G.; BULL, L. T.; CRUSCIOL, C. A. C. Atributos químicos do solo, crescimento radicular e produtividade do arroz de acordo com a aplicação de escórias. Pesquisa Agropecuária Brasileira, Brasília, v. 39, n. 12, p. 1213-1218, dez. 2004.
CRANSHAEW, W. S.; RADCLIFFE, E. B. Effect of defoliation on yield of potatoes. Journal of Economic Entomology, Lanhan, v. 73, n. 1, p. 131-134, Feb. 1980.

DAROLT, M. R.; RODRIGUES, A.; NAZARENO, N.; BRISOLLA, A.; RÜPPEL, O. Análise comparativa entre o sistema orgânico e convencional de batata comum. 2003. Disponível em: i<http://Lww.planetaorganico.com.bri 'Daroltbatata.htm?. Acesso em: 25 jan. 2007.

DÉLANO-FRIER, J. P.; MARTÍNEZ-GALLARDO, N. A.; DE LA VEGA, O. M.; SALAS-ARAIZA, M. D.; VARGAS, P.; BORODANENKO, A. The effect of exogenous jasmonic acid on induced resistance and productivity in amaranth (Amaranthus hypochondriacus) is influenced by environmental conditions. Journal of Chemical Ecology, New York, v. 30, n. 5, p. 1001-1034, May 2004.

EPSTEIN, E. Silicon in plants: facts vs concepts. In: DATNOFF, L. E.; SNYDER, G. H.; KORNDÖRFER, G. H. (Eds.). Silicon in agriculture. The Netherlands: Elsevier Science, 2001. 403 p.

FAWE, A.; MENZIES, J. G.; CHERIF, M.; BÉLANGER, R. R. silicon and disease resistance in dicotyledons. In: DATNOFF, L. E.; SNYDER, G. H.; KORNDÖRFER, G. H. (Eds.). Silicon in agriculture. The Netherlands: Elsevier Science, 2001. 403 p.

GASSEN, D. N. Insetos subterrâneos prejudiciais às culturas no sul do Brasil. Passo Fundo: Embrapa CNTP/ OCEPAR, 1989. 72 p. (Documento, 13).

GOMES, F. B.; MORAES, J. C.; SANTOS, C. D.; GOUSSAIN, M. M. Resistance induction in wheat plants by silicon and aphids. Scientia Agricola, Piracicaba, v. 62, n. 6, p. 547-551, nov./dez. 2005.

GOUSSAIN, M. M.; MORAES, J. C.; CARVALHO, J. G.; NOGUEIRA, N. L.; ROSSI, M. L. Efeito da aplicação de silício em plantas de milho no desenvolvimento biológico da lagarta do cartucho Spodoptera frugiperda (J. E. Smith) (Lepidoptera: Noctuidae). Neotropical Entomology, Londrina, v. 31, n. 2, p. 305310, 2002.

INSTITUTO AGRONÔMICO DO PARANÁ. Agronegócio do Paraná: perfil e caracterização das demandas das cadeias produtivas. Londrina, 2000. (Documento, 24). 
INSTITUTO BIODINÂMICO. A agricultura orgânica no Brasil. Disponível em: Khttp://www.ibd.com.br/artigos/ lagricultura organica Brasil.htm $\mid>$. Acesso em: 25 jan. 2007.

JARVIS, S. C. The uptake and transport of silicon by perennial ryegrass and wheat. Plant soil, Dordrecht, v. 97, n. 2/3, p. 429-437, 1987.

KORNDÖRFER, G. H.; PEREIRA, H. S.; CAMARGO, M. S. Papel do silício na produção de cana-de-açúcar. STAB, Piracicaba, v. 21, n. 2, p. 34-37, dez. 2002.

MA, J. F.; MIYAKE, Y.; TAKAHASHI, E. Silicon as a beneficial element for crop lants. In: DATNOFF, L. E.; SNYDER, G. H.; KORNDÖRFER, G. H. (Eds.). Silicon in agriculture. The Netherlands: Elsevier Science, 2001. 403 p.

NERI, D. K. P. Efeito do silício na resistência de plantas de milho a Rhopalosiphum maidis (Fich.) (Hemiptera: Aphididae) e sua interação com inseticida no controle de Spodoptera frugiperda (J. E. Smith) (Lepidoptera: Noctuidae). 2006. 68 p. Tese (Doutorado em Agronomia/ Entomologia) - Universidade Federal de Lavras, Lavras, 2006.

NOJOSA, G. B. A.; RESENDE, M. L. V.; RESENDE, A. V. Uso de fosfitos e silicatos na indução de resistência. In: CAVALCANTI, L. S. et al. (Eds.).Indução de resistência em plantas a patógenos e insetos. Piracicaba: FEALQ, 2006. 263 p.

PARRELLA, M. P.; COSTAMAGNA, T. The addition of potassium silicate to the fertilizer mix to suppress Liriomyza leafminers attacking chrysanthemums. BulletinOILB/SROP, Dijon, v. 29, n. 4, p. 159-162, 2006.

PETITT, F. L.; SMILOWITZ, Z. Green peach aphid feeding damage to potato in various plant growth stages. Journal of Economic Entomology, Lanhan, v. 75, n. 3, p. 431-435, June 1982.
PINTO, R. M.; BUENO, V. H. P.; SANTA-CECÍLIA, L. V. C. Flutuação populacional de afídeos (Hemiptera: Aphididae) associados à cultura da batata, Solanum tuberosum L., no plantio de inverno em Alfenas, sul de Minas Gerais. Anais da Sociedade Entomológica do Brasil, Jaboticabal, v. 29, n. 4, p. 649-657, dez. 2000.

PLUCKNETT, D. L. The use soluble silicates in Hawaii agriculture. University of Queensland, Havaii, v. 1, n. 6, p. 203-223, 1971.

SCOTT, A. J.; KNOTT, M. A. Acluster analysis method for gruping means in the analysis of varianicis. Biometrics, Washington, v. 30, n. 3, p. 507-512, Sept. 1974.

SILVA, L. S. da; BOHNEN, H. Produtividade e absorção de nutrientes pelo arroz cultivado em solução nutritiva com diferentes níveis de silício e cálcio. Revista Brasileira de Agrociência, Pelotas, v. 9, n. 1, p. 49-52, jan./abr. 2003.

SOUZA-DIAS, J. A. C. Viroses da batata e suas implicações na produção de batata-semente no estado de São Paulo. Summa Phytopathologica, Piracicaba, v. 21, n. 3/4, p. 264266, jul./dez. 1995.

SOUZA, J. C. de; SALGADO, L. O.; RIGITANO, R. L. de; REIS, P. R. Danos causados pela mosca-minadora Liriomyza huidobrensis Blanchard, 1926 (Diptera:Agromyzidae) na cultura da batata Solanum tuberosum L., no plantio de inverno no Sul de Minas Gerais, e eficiência do aldicarb no seu controle. Ciência e Agrotecnologia, Lavras, v. 22, n. 1, p. 22-29, jan./mar. 1998.

SOUZA, J. L. de; RESENDE, P. Manual de horticultura orgânica. Viçosa: Aprenda Fácil, 2003. 564 p.

YOSHIDA, S.; OHNISHI, Y.; KITAGISHI, K. Histochemistry of silicon in rice plant. Soil Science and Plant Nutition, Tokyo, v. 8, p. 107-111, 1962. 